\title{
Computational study on the Rh-catalyzed chemodivergent oxidative annulation of benzamides and enynes
}

\author{
Jing Zhang ${ }^{1}$, Qingli Zhang ${ }^{2}$, Zhenyuan Zhu ${ }^{1}$, and Bingkai Wang ${ }^{1}$ \\ ${ }^{1}$ Jining University \\ ${ }^{2}$ China People's Police University
}

May 5, 2020

\begin{abstract}
The mechanisms of $\mathrm{Cp} * \mathrm{Rh}(\mathrm{OAc}) 2$-catalyzed coupling reaction of $\mathrm{N}$-methoxybenzamide with alkyl-terminated enyne have been investigated by density functional theory (DFT) calculations. With the addition of NaOAc and changing solvent, the product transforms from lactam P1 in reaction A to iminolactone P2 in reaction B, due to the formed stable OAc- coordinated intermediate. The electronic effect and steric effect account for the observed regioselectivity in reaction B collectively.
\end{abstract}

\section{Hosted file}

ms-QUAN-revision.docx available at https://authorea.com/users/293104/articles/421011computational-study-on-the-rh-catalyzed-chemodivergent-oxidative-annulation-ofbenzamides-and-enynes 